\title{
AS INDICAÇÕES GEOGRÁFICAS COMO FORMA DE VALORIZAÇÃO DOS ATRIBUTOS TERRITORIAIS DE PRODUTOS ALIMENTARES
}

\author{
Alini Nunes de Oliveira \\ Professora do Departamento de Gestão e Hospitalidade \\ Instituto Federal de Mato Grosso - IFMT \\ alini nunes@hotmail.com
}

\begin{abstract}
RESUMO
As indicações geográficas surgem, no contexto europeu, da necessidade de se distinguir os produtos no mercado afim de evitar falsificações e como forma de valorizar os atributos territoriais. No Brasil, a legislação mais recente sobre este sistema de propriedade industrial remonta o final da década de 1990 e pretende identificar e valorizar a origem e a qualidade de produtos e serviços, inerentes ao território em que são produzidos. No caso dos produtos alimentares, os produtores podem obter vantagens com esta forma de certificação no sentido de que agrega valor ao seu produto frente ao mercado e, aos consumidores, também é proporcionado benefícios, pois esta é uma forma de possivelmente adquirir produtos com características distintas e, muitas vezes, melhor qualidade. A presente pesquisa teve como objetivo expressar como o processo de registro das indicações geográficas pode contribuir para a valorização dos atributos territoriais de produtos alimentares. Para a construção deste artigo utilizou-se como procedimento metodológico a pesquisa bibliográfica e documental. Ao final do artigo foi possível conhecer um panorama atual das indicações geográficas brasileiras, o contexto e histórico de surgimento, características e benefícios, assim como os produtos já registrados.
\end{abstract}

Palavras-chave: Indicação de procedência. Denominação de origem. Produtos alimentares.

\section{GEOGRAPHICAL INDICATIONS AS A MEANS TO VALUE TERRITORIAL ATTRIBUTES OF FOOD PRODUCTS}

\begin{abstract}
Geographical indications emerge, in the European context, from the need to distinguish products on the market to avoid falsifications, and as a means to value territorial attributes. In Brazil, the most recent legislation on this industrial property system dates back to the late 1990 s and aims to identify and value the origin and quality of products and services inherent in the territory in which they are produced. With regard to food products, producers can make a profit on this form of certification as it adds market value for their products. Similarly, consumers can benefit since they have the possibility of purchasing differentiated products, often of better quality. In this sense, this research aims to discuss how the process of registering geographical indications can contribute to value territorial attributes of food products. To do so, bibliographic and documentary research were used as methodological procedures. The paper provides an overview of the Brazilian geographical indications, the context and history of their emergence. It also identifies the characteristics and advantages of geographical indications as well as the products that have already been registered.
\end{abstract}

Keywords: Origin indication. Designation of origin. Food products.

\section{INTRODUÇÃO}

A cultura de massa a que as sociedades atuais estão submersas, muitas vezes, padroniza os hábitos de consumo, tanto material quanto simbólico. No âmbito da alimentação, encontram-se rodeados de produtos alimentares padronizados, de pouca qualidade nutricional e organoléptica, vazios de sentido identitário e que pouco acrescentam para além da saciedade fisiológica.

$\begin{array}{llllll}\text { Caminhos de Geografia } & \text { Uberlândia-MG } & \text { v. 22, n. } 83 & \text { out./2021 } & \text { p. 47-.65 } & \text { Página } 47\end{array}$


A acirrada disputa no mercado internacional pela atenção dos consumidores e para obter produtos com valores mais competitivos, têm estimulado a homogeneização da produção alimentícia em inúmeros países, resultando numa concorrência desleal frente aos pequenos produtores. Neste contexto, surgem grupos de pessoas interessadas em consumir diferente, produzir diferente, ligadas às questões de qualidade do produto, mas também das relações de trabalho, das relações com o meio ambiente, dos atributos culturais, muitos deles inerentes ao território, num espectro mais amplo.

Os novos hábitos de consumo deste público, cada vez mais consciente e exigente, têm estimulado muitos produtores a buscarem o reconhecimento, por meio de certificações, que diferenciem produtos e serviços como forma de estabelecer maior confiança dos consumidores e para valorizar seus produtos frente à concorrência. O registro de indicações geográficas é apenas uma de várias formas de se alcançar tal propósito.

A presente pesquisa teve como objetivo expressar como o processo de registro das indicações geográficas pode contribuir para a valorização dos atributos territoriais de produtos alimentares. Além disso, buscou-se descrever um panorama atual das indicações geográficas brasileiras, resgatando seu histórico de surgimento na Europa e delineando suas características e benefícios no contexto brasileiro.

Para a construção deste artigo utilizou-se como procedimento metodológico a pesquisa bibliográfica (que contemplou livros, dissertações, teses e artigos científicos publicados em periódicos e anais de eventos) e documental (a partir de sites institucionais, base de dados do INPI e da União Europeia, relatórios e outros documentos oficiais, reportagens de jornais etc.).

\section{CONTEXTO DE SURGIMENTO DAS INDICAÇÕES GEOGRÁFICAS}

Imersa em um cenário socioeconômico e cultural que é, em partes, globalizado, grande parcela da sociedade atual, caracterizada pelo consumo (in)conscientemente exacerbado, convive com a produção em larga escala que, dentre outras consequências, acarreta na estandardização dos produtos e homogeneização/descaracterização das culturas. Vive-se, como salienta Lipovetsky (2007), a era do hiperconsumo, ou seja, quanto mais a sociedade enriquece, maior o consumo e as necessidades de consumir.

Se, por um lado, em um contexto global, há o aumento no volume de trocas comerciais e importações de produtos diversos (seja agrícola, industrial ou tecnológico), que na maior parte das vezes chegam aos consumidores com preços muito abaixo dos praticados quando se refere a produtos nacionais/locais similares e muitas vezes de qualidade duvidosa, por outro, nos últimos vinte anos, vem despontando um nicho de consumidores que busca por produtos diferenciados, que prezam pela qualidade e também por sua diferenciação entre os demais, que valorize os produtores locais e os recursos territoriais. Segundo Altmann:

Os consumidores desejam saber hoje o que estão comendo, quem produziu, como se produziu, se o meio ambiente foi respeitado, se há ética no negócio e, sobretudo, se não é prejudicial à saúde. Tornam-se, a cada dia, mais exigentes quanto à qualidade dos alimentos que compram e, assim, vão delineando um novo perfil de consumo (ALTMANN, 2005, p. 134).

Como salienta Dias (2005), essa importância dada a produtos diferenciados não é um fenômeno acidental ou temporário, mas sim uma evolução do modelo de sociedade, com aumento dos níveis de instrução da população, mais tempo para o lazer, acesso mais ampliado às redes de comunicações, maior interesse por se reconectar com a natureza e com a saúde, busca pelo que é tradicional, que crie vínculos com o local de origem e voltadas a conservação das culturas.

Quando o enfoque são os produtos alimentares, há três pontos importantes a se considerar: 1) a intensificação da internacionalização da alimentação, devido aos avanços nos processos de produção, conservação, acondicionamento e transporte de alimentos, provocou o deslocamento de produtos (perecíveis ou não) a grandes distâncias entre o centro produtor e o centro consumidor, causando, em partes, um estranhamento na população quanto à sua origem, gerando insegurança quanto aos processos de fabricação e também quanto à qualidade (KRONE e MENASCHE, 2009, 2010); 2) por muito tempo se valorizou os produtos importados (por exemplo, por serem considerados de melhor qualidade ou

$\begin{array}{llllll}\text { Caminhos de Geografia } & \text { Uberlândia-MG } & \text { v. 22, n. } 83 & \text { out./2021 } & \text { p. 47-65 } & \text { Página } 48\end{array}$


por status, ou seja, ter poder aquisitivo o suficiente para consumi-los, já que normalmente eram/são mais caros), em detrimento aos produtos locais; e 3) há, em partes, um desconhecimento dos consumidores no sentido de não se conectarem com a cadeia produtiva dos alimentos (SANTOS e MENASCHE, 2015), em que estes, já estão intensamente desterritorializados, ou conforme Poulain (2004), deslocados de seu enraizamento geográfico, quando perdem seus atributos culturais.

É neste contexto que os produtos regionais, sobretudo os que de alguma forma apresentam certificações, reconhecimento de origem ou similares, começam a ter maior visibilidade. Embora recente no Brasil, em âmbito mundial, principalmente em países europeus, movimentos sociais e ambientais contrários às imposições do sistema capitalista, já há mais tempo buscam novas formas de consumo, de certo modo mais justas, mais críticas, conscientes e saudáveis, repensando também as relações entre rural e urbano.

O Slow Food, fundado em 1986 na Itália, é um movimento que se opõe à padronização dos alimentos e tem como princípio básico "[...] o direito ao prazer da alimentação, utilizando produtos artesanais de qualidade especial, produzidos de forma que respeite tanto o meio ambiente quanto as pessoas responsáveis pela produção, os produtores" (SLOW FOOD, 2020, s/p).

O Fair Trade, ou comércio justo, bastante difundido na Europa a partir da década de 1960, é um movimento do comércio ético e solidário,

[...] baseado em princípios como erradicação do trabalho infantil exploratório e do trabalho escravo, eliminação das discriminações de raça, gênero e religião, preservação da saúde das pessoas e do ambiente, eliminação dos níveis de intermediação comercial especulativa, garantia do pagamento de preços justos aos pequenos produtores, respeito aos direitos trabalhistas, respeito às identidades históricas e culturais locais e regionais, valorização das dimensões não geográficas do território [...], entre outros (ALMEIDA, 2005, p. 216-217).

Já o Locavorismo é um movimento alimentar que emergiu nos Estados Unidos em meados da década de 2000 que [...] preocupa-se não somente onde a comida é produzida, mas como e por quem e também quem a comercializa" (AZEVEDO, 2015, p. 81). Segundo a autora, o movimento busca inserir na discussão as feiras e pequenos comércios liderados pelos agricultores, estabelecendo relações mais estreitas entre consumidores e produtores. Em alguns casos, o consumidor adquire produtos que podem ser colhidos diretamente do campo.

Também pode-se incluir neste contexto a agricultura familiar que, segundo a FAO (2020, s/p), neste tipo de sistema agrícola "[...] a gestão da propriedade é compartilhada pela família e a atividade produtiva agropecuária é a principal fonte geradora de renda. Além disso, o agricultor familiar tem uma relação particular com a terra, seu local de trabalho e moradia".

Os sistemas de produção de base ecológica surgem em um momento em que, em resposta ao modelo agrícola produtivista, a partir de 1920, organizam-se movimentos contrários à agricultura convencional, de forma a estabelecer práticas menos agressivas ao meio ambiente, respeitando a saúde dos produtores e consumidores, otimizando os serviços ambientais e prezando os anseios sociais, como a agricultura orgânica, biodinâmica, biológica e natural (LOPES e LOPES, 2011).

Pesquisadores também encontram termos importantes que convergem para estas práticas que buscam um outro modo de consumir alimentos e de valorizar o trabalho. Termos como produtos tradicionais, produtos típicos (coloniais) ou produtos da terra (estes recebem diferentes denominações ao longo de pesquisas acadêmicas de diferentes áreas do conhecimento), são resultado da aplicação de conhecimentos tradicionais, ou seja, embora não haja uma definição única, "[...] genericamente pode dizer-se que está relacionado ao conhecimento integrado gerado ao longo do tempo a partir de crenças, práticas comunitárias e identidade cultural. [...] Ele evolui ao longo do tempo e está enraizado nos sistemas de conhecimentos tradicionais que cada comunidade desenvolve e mantém no seu contexto local" (DIAS, 2005, p. 81-82). O produto alimentar típico, segundo Mariot (2002, p. 17), é o "Produto processado obtido em pequena escala ao nível da propriedade rural ou pequenas indústrias rurais, usando matérias primas locais e tecnologia de elaboração tradicional". De acordo com Krone e Menasche (2009, p. 2), produtos da terra são "[...] alimentos cuja procedência e/ou processo de produção são conhecidos do consumidor, alimentos produzidos localmente, a partir de procedimentos avaliados como ambiental, social e economicamente sustentáveis, enraizados em um território e em uma cultura [...]".

$\begin{array}{llllll}\text { Caminhos de Geografia } & \text { Uberlândia-MG } & \text { v. 22, n. } 83 & \text { out./2021 } & \text { p. 47-65 } & \text { Página } 49\end{array}$


A busca pela qualidade dos alimentos não está diretamente relacionada ao que se vê ou ao que se sente, mas também a outras características, conforme salienta Velloso:

\begin{abstract}
A qualidade não é mais somente aquela intrínseca ao produto e "diretamente visível", como o seu aspecto físico (textura, cor etc.) e suas características organolépticas (aromas, sabores...). Ela pode ser também atribuída ao modo de produção e à sua origem. $E$ as exigências neste caso são também de ordem social e ambiental, pelo respeito aos direitos humanos e aos recursos ambientais, ou mesmo da valorização da produção tradicional, artesanal, de culturas, patrimônios e saberes específicos (VELLOSO, 2008, p. 32).
\end{abstract}

O mercado mundial de alimentos está em constantes transformações, sobretudo a partir das crises alimentares na Europa no início da década de 1990 (doenças, uso abusivo de agroquímicos, problemas sanitários etc), com repercussão em todo o mundo (ALTMANN, 2005). As discussões acerca de novos hábitos alimentares - hábitos de consumo de maneira geral - podem ser compreendidas por meio destes movimentos e formas alternativas de produzir e se relacionar com os alimentos.

Estes produtos usualmente trazem em si a identidade local, desde características do território em que está localizado, até aspectos culturais das pessoas envolvidas em sua cadeia produtiva. Parte dos consumidores tem despertado para um consumo mais consciente, o que acarreta, muitas vezes, em engajamento na busca por produtos fabricados localmente, de forma que seja possível estreitar os laços entre produtor e consumidor. Neste contexto, a indicação geográfica é um meio de os consumidores encontrarem produtos diferenciados.

\title{
AS INDICAÇÕES GEOGRÁFICAS
}

A noção de indicação geográfica (IG) não é nova e seu conceito foi se desenvolvendo ao longo da história. Para compreender o surgimento das IG no Brasil, é preciso compreender seus antecedentes. A diferenciação da qualidade de certos produtos devido à sua origem remonta aos tempos bíblicos, com indicações de sinais distintivos de uma origem, como os vinhos de En-Gedi e o cedro do Líbano. Na Grécia antiga, relatos que remontam ao século IV a.C., mencionam produtos como os vinhos de Corinto, de Ícaro e de Rodhes, o mel da Sicília, as amêndoas de Naxos e o mármore de Paros, enquanto que na Roma antiga, as ostras de Brindisi, as tâmaras do Egito, o presunto de Gália, o mármore de Carrara e o vinho de Falerne, eram produtos também reconhecidos por sua origem (BERTOZZI, 1995; GURGEL, 2004; MEDEIROS, 2015).

$\mathrm{Na}$ Europa, o reconhecimento da origem e qualidade dos produtos precisou ser formalizado, dentre outros motivos, devido às falsificações que passaram a ocorrer após a fama destes produtos no mercado, que possuíam maior valor agregado. Em 1666, a França foi o primeiro país a redigir um documento jurídico versando sobre a denominação de origem dos queijos, especificamente ao Roquefort (KRÜCKENPEREIRA, 2001). Mas, em se tratando de uma IG legalmente reconhecida e delimitada por intervenção estatal, foi a região do Douro, em Portugal, em 1756, a pioneira, quando produtores de Vinho do Porto procuraram o então governante Marquês de Pombal solicitando auxílio quanto à queda nas vendas deste produto, pois, com a notoriedade que este vinho havia adquirido, muitos falsificadores começaram a atuar no mercado com bebidas de origem desconhecida utilizando a denominação "do Porto". Como forma de proteção, foi necessário descrever seu processo de produção com exatidão, definindo etapas, fixando as características e instituindo regras para a fabricação do Vinho do Porto. Com o registro por decreto, esta foi a primeira Denominação de Origem Protegida (PIMENTEL, 2014).

Em 1992, a União Europeia (UE) estabeleceu um sistema de proteção para nomes geográficos, sofrendo alterações e ajustes no decorrer dos anos. Conforme tabela 01, atualmente, as indicações geográficas estão subdivididas em: denominações de origem protegidas (DOP) e indicações geográficas protegidas (IGP) para produtos agrícolas, alimentos e vinhos; e indicações geográficas (IG), para bebidas destiladas e vinhos aromatizados (EUROPEAN, 2020a). Além destes, há ainda a especialidade tradicional garantida (ETG), voltada à proteção de produtos agrícolas e alimentícios, mas não necessariamente ligados ao território, mas sim aos modos de fazer e sua composição.

$\begin{array}{llllll}\text { Caminhos de Geografia } & \text { Uberlândia-MG } & \text { v. 22, n. } 83 & \text { out./2021 } & \text { p. 47-65 } & \text { Página } 50\end{array}$


Tabela 1 - Subdivisões das indicações geográficas na União Europeia.

\begin{tabular}{|c|c|c|}
\hline Tipo & $\begin{array}{c}\text { Especificações } \\
\end{array}$ & Exemplo \\
\hline $\begin{array}{l}\text { Denominação } \\
\text { de origem } \\
\text { protegida (DOP) }\end{array}$ & $\begin{array}{l}\text { São os produtos que têm ligações mais fortes com o } \\
\text { território em que são fabricados. Todas as fases de } \\
\text { produção, transformação e preparação devem ser } \\
\text { localizadas na região delimitada. } \\
\text { Referente aos vinhos, as uvas devem ser provenientes } \\
\text { exclusivamente da área geográfica onde são produzidos. }\end{array}$ & $\begin{array}{l}\text { O azeite Kalamata é produzido } \\
\text { integralmente nesta região da Grécia, } \\
\text { utilizando-se várias variedades de } \\
\text { azeitona localizadas nesta área. }\end{array}$ \\
\hline $\begin{array}{l}\text { Indicação } \\
\text { geográfica } \\
\text { protegida (IGP) }\end{array}$ & 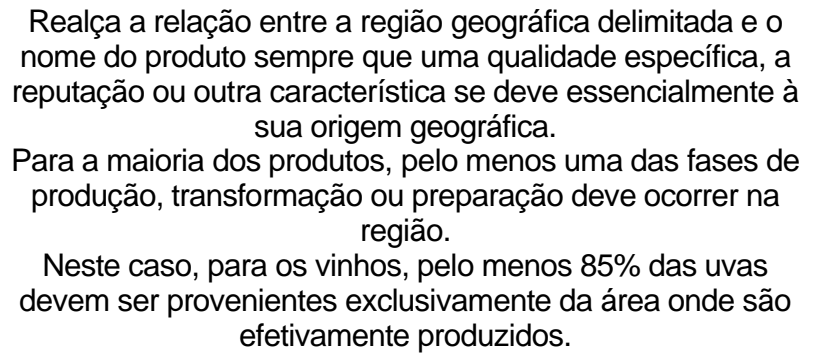 & $\begin{array}{l}\text { O presunto Westfälischer } \\
\text { Knochenschinken é produzido na } \\
\text { região de Vestefália, Alemanha, por } \\
\text { meio de técnicas ancestrais, mas a } \\
\text { carne utilizada não provém } \\
\text { exclusivamente de animais dessa } \\
\text { região específica. }\end{array}$ \\
\hline $\begin{array}{l}\text { Indicação } \\
\text { geográfica para } \\
\text { bebidas } \\
\text { destiladas e } \\
\text { vinhos } \\
\text { aromatizados } \\
\text { (IG) }\end{array}$ & $\begin{array}{c}\text { Protege o nome de uma bebida destilada ou de um vinho } \\
\text { aromatizado originário de um país, região ou localidade } \\
\text { sempre que uma qualidade específica, a reputação ou outra } \\
\text { característica se deve essencialmente à sua origem } \\
\text { geográfica. } \\
\text { Para a maioria dos produtos, pelo menos uma das fases de } \\
\text { destilação ou preparação ocorre na região. Porém, não é } \\
\text { necessário que as matérias-primas sejam provenientes da } \\
\text { mesma região. }\end{array}$ & $\begin{array}{l}\text { O Irish Whiskey é produzido na Irlanda } \\
\text { desde o séc. VI. No entanto, as } \\
\text { matérias-primas não são provenientes } \\
\text { exclusivamente deste país. }\end{array}$ \\
\hline $\begin{array}{l}\text { Especialidade } \\
\text { tradicional } \\
\text { garantida (ETG) }\end{array}$ & $\begin{array}{c}\text { Salienta aspectos ligados às tradições, por exemplo, a } \\
\text { forma como o produto é fabricado ou a sua composição, } \\
\text { sem estar necessariamente associada a uma região } \\
\text { geográfica previamente delimitada. Um produto registado } \\
\text { como ETG fica protegido contra a falsificação e uma } \\
\text { utilização indevida. }\end{array}$ & $\begin{array}{c}\text { A Gueuze é uma cerveja tradicional } \\
\text { obtida por fermentação espontânea, } \\
\text { geralmente produzida em Bruxelas } \\
\text { (Bélgica) e região. No entanto, } \\
\text { tratando-se de uma ETG, o seu } \\
\text { método de produção está protegido, } \\
\text { mas a produção pode ocorrer em } \\
\text { outra região. }\end{array}$ \\
\hline
\end{tabular}

Fonte - EUROPEAN (2020, s/p).

No contexto europeu, estes programas de qualidade são uma importante ferramenta de valorização de produtos regionais, atribuindo a estes produtos vantagens econômicas, socioculturais e ambientais, que na seção a seguir serão discutidos com maior profundidade. As IG têm sido utilizadas como instrumentos de diferenciação de produtos perante a concorrência entre países, empresas e organizações de produtores de diferentes regiões. Conforme salienta Gurgel:

\begin{abstract}
[...] Os países desenvolvidos da Europa trabalharam historicamente muito bem essa proteção, através do incremento de capital social e humano como forma de divulgar a peculiaridade territorial e diferencial competitivo, usando-o como instrumento de desenvolvimento local e da preservação da identidade cultural da comunidade (GURGEL, 2004, p. 47).
\end{abstract}

Segundo relatório da World Intellectual Property Organization (WIPO, 2020), a partir de dados enviados por 82 autoridades nacionais/regionais, em 2017, havia aproximadamente 59.500 produtos protegidos em vigor em todo o mundo. A Alemanha registrou o maior número (14.073), seguida pela Áustria (8.749), China (8.507), Hungria (6.646), República Tcheca (6.191), Bulgária (6.096) e Itália (5.977). Do total em vigor em 2017, as relacionadas a vinhos e bebidas destiladas representaram cerca de $57 \%$, seguidas por produtos agrícolas e alimentícios $(28,2 \%)$ e artesanato $(2,7 \%)$. Vale ressaltar que o envio destes dados à WIPO abrangia várias formas de proteção (não apenas as indicações geográficas estabelecidas pela União Europeia), como sistemas sui generis, sistemas de marcas registradas, outros meios legais nacionais específicos, sistemas regionais e acordos internacionais (incluindo as IG em vigor no âmbito do Acordo de Lisboa e do Acordo de Madri), como a França, por exemplo, que apresenta quatro programas de qualidade para alimentos: Apelação de Origem Controlada (AOC), Selo Vermelho, Agricultura Biológica (AB) e a Certificação de Conformidade de Produto (CCP) (BRABET e PALLET, 2005). O que se pretendeu ao apresentar estes dados, é a relevância que a proteção de produtos regionais tem neste contexto, não necessariamente com características restritas ao território.

Importante salienta que o Brasil, assim como outros países da América Latina, em comparação com a União Europeia, têm muito a crescer ainda em se tratando de relações comerciais de produtos protegidos. Para se ter uma ideia, "Em termos monetários, o mercado das indicações geográficas da UE atinge cerca de 74,8 mil milhões de EUR, representando $15,4 \%$ do total das exportações de bebidas e alimentos da
Caminhos de Geografia
Uberlândia-MG
v. 22, n. 83
out./2021
p. 47-65
Página 51 
UE" (ACORDO, 2019, s/p). No mundo, as IG movimentam bilhões de dólares por ano e há ainda muito espaço para crescimento, em se tratando de benefícios econômicos (BOLFE, 2019).

Para além do território europeu, na América Latina existem iniciativas para assegurar a proteção de seus produtos. No México, desde 1974, há proteção legal da tequila, bebida destilada produzida a partir de agave-azul. O café Veracruz também é uma denominação de origem mexicana que garante a qualidade do café produzido nesta região e o tornou forte produtor deste grão. No Peru, em 1990, o pisco - bebida destilada produzida a partir de uvas maduras - foi promulgado pelo Estado peruano como denominação de origem daquele país. Na Bolívia, desde 1992, o singani, aguardente de uva moscatel da região de Potosí, foi estabelecida com o uso de denominação de origem. Em 2000, a Venezuela reconheceu como denominação de origem o cacau de Chuao, este, um dos primeiros povoados fundados na Venezuela, na metade do século XVI (CALDAS, 2003; CALDAS; CERQUEIRA; PERIN, 2005; CARVALHO e DIAS, 2012; MEDEIROS, 2015).

A Ásia também tem se destacado com uma expressiva quantidade de produtos protegidos por IG, como o chá Darjeeling da índia, o vinho amarelo de Shaixing da China, o chá do Ceilão (Sri Lanka) etc. (LIMA; IESBRECHT; LIMA, 2007; VALENTE et al., 2012). Na Índia, para se ter uma ideia, até março de 2020, havia 361 produtos agrícolas, alimentícios, manufaturados e artesanatos protegidos (ÍNDIA, 2020).

$\mathrm{Na}$ África, são reconhecidos por sua origem, por exemplo, o óleo de Aragan do Marrocos, o abacaxi da Guiné, gari missè (sêmola fermentada de mandioca) de Savalou no Benin, arroz de montanha de Man na Costa do Marfim, pimenta Mamou e óleo de palma Boké da Guiné, mel branco de Oku no Camarões, o cordeiro de Karoo e o chá de Rooibos na África do Sul (SALTIER; BIÉNABE; CERDAN, 2011). No caso do continente africano, além de marcas comerciais, patentes e design de produtos, como na Europa, a African Regional Intellectual Property Organization (ARIPO), organização composta por 19 paísesmembros deste continente, instituiu em 2010 o Protocolo de Swakopmund, que versa sobre a proteção dos conhecimentos tradicionais e expressões do folclore (AFRICAN, 2020). De acordo com VargasChaves (2014), esta foi a primeira ferramenta internacional de proteção de conhecimentos tradicionais e que poderia ser ampliado em um alcance global, principalmente aos casos que se encontram em estado vulnerável e que exigem proteção imediata por meio de políticas públicas.

Voltando ao caso europeu, embora alguns países tivessem criado suas próprias legislações quanto à proteção de produtos locais, ao se tratar de comércio internacional, estas leis não se tornaram tão efetivas quanto à falsificação e uso indevido de nomenclaturas por outros países de fora do continente. Destarte, por iniciativa de países produtores de vinhos, estes organizaram um tratado constitutivo da Convenção União de Paris para a Proteção da Propriedade Industrial (CUP) (DIAS, 2005), cuja adesão do Brasil ocorreu em 1884, por meio do Decreto-lei $n^{\circ} 9.233$. Este documento, na ocasião, já versava sobre as indicações geográficas (embora utilizando o termo indicação de procedência). Anos mais tarde, com os avanços na legislação de proteção intelectual, este tratado foi atualizado por meio do Acordo de Madri (1891) - assinado pelo Brasil em 1896 - e do Acordo de Lisboa (1958) - sem adesão do governo brasileiro até o momento.

Em 1967, estes acordos passaram a ser administrados pela Organização Mundial da Propriedade Intelectual (OMPI ou WIPO, sigla em inglês), agência especializada ligada à Organização das Nações Unidas (ONU). Com a criação da Organização Mundial do Comércio (OMC) em 1994, os assuntos envolvendo a proteção da propriedade intelectual (incluindo as IG) também se voltam às relações comerciais e tarifárias internacionais, sendo assim, assinado o Acordo sobre Aspectos dos Direitos de Propriedade Intelectual Relacionados ao Comércio (ADIPC ou TRIPS, sigla em inglês), acordo este obrigatoriamente assinado por todos os países-membro da OMC (BARROS e VARELLA, 2004; GURGEL, 2004, CALLIARI et al., 2007; PIMENTEL, 2014; MEDEIROS, 2015).

No Brasil, as IG estão dentro dos gêneros de propriedade intelectual como sinais distintivos. Embora os sinais distintivos aparecessem em outros documentos anteriores ao atual em vigência, como o Decreto $n^{\circ}$ 9.333 de 1884, a Constituição Federal de 1891 e os Decretos n 24.507 de 1934 e n 7.903 de 1945 (GURGEL, 2004), somente a partir da década de 1990 é que se começa a discutir sobre as IG da forma como se conhece hoje, com a Lei de Propriedade Intelectual, lei $n^{\circ} 9.279$ instituída em 14 de maio de 1996 (MEDEIROS e PASSADOR, 2015). Tecnicamente, a IG "é um nome geográfico que identifica um produto ou serviço como originário de uma área geográfica delimitada quando determinada qualidade, reputação ou outra característica é essencialmente atribuída a essa origem geográfica" (SEBRAE, 2019, p. 6). Nesta lei fica mais clara a distinção do gênero indicações geográficas em duas espécies: indicação de procedência (IP) e denominação de origem (DO). De acordo com os artigos 177 e 178 desta lei:

Art. 177. Considera-se indicação de procedência o nome geográfico de país, cidade região ou localidade de seu território, que se tenha tornado conhecido como centro de extração, produção ou fabricação de determinado produto ou de prestação de determinado serviço.

Art. 178. Considera-se denominação de origem o nome geográfico de país, cidade, região ou localidade de seu território, que designe produto ou serviço cujas qualidades ou características se devam exclusiva ou essencialmente ao meio geográfico, incluídos fatores naturais e humanos (BRASIL, 2020, s/p). 
Um grande diferencial da legislação brasileira perante as demais em âmbito internacional é a inclusão de serviços como uma possibilidade de proteção. No que se refere às principais diferenças e semelhanças entre as duas espécies de IG, na tabela 2 apresenta-se um comparativo:

Tabela 2 - Características das espécies de indicação geográfica no Brasil.

\begin{tabular}{ccc}
\hline Características & Indicação de procedência & Denominação de origem \\
\hline $\begin{array}{c}\text { Vínculo com o } \\
\text { meio geográfico }\end{array}$ & $\begin{array}{c}\text { Relaciona-se com a notoriedade da origem de } \\
\text { determinado produto/serviço quanto ao seu processo de } \\
\text { extração, produção ou fabricação, ou seja, o quanto a } \\
\text { região é reconhecida por determinado produto/serviço. }\end{array}$ & $\begin{array}{c}\text { Seu reconhecimento refere-se às } \\
\text { peculiaridades físicas e humanas } \\
\text { (desde que identificáveis e } \\
\text { mensuráveis), que lhes confere } \\
\text { características únicas de qualidade. }\end{array}$ \\
\hline $\begin{array}{c}\text { Vínculo com o } \\
\text { processo de } \\
\text { produção/ } \\
\text { fabricação }\end{array}$ & $\begin{array}{c}\text { Não é necessário, pois seu reconhecimento está atrelado } \\
\text { à fama que determinado produto/serviço tem, por conta de } \\
\text { sua concentração em determinado local. }\end{array}$ & $\begin{array}{c}\text { Neste caso, as características físicas } \\
\text { (clima, solo, relevo etc.) e humanas } \\
\text { (saber-fazer, manifestações culturais, } \\
\text { história local etc.) locais são } \\
\text { responsáveis por sua singularidade. }\end{array}$ \\
\hline
\end{tabular}

\section{Complexidade do processo de documentação}

Menor necessidade de documentação em comparação à DO.
Processo mais complexo de obtenção de documentação, já que depende de pesquisas científicas como análise organolépticas, de solo, de influência do clima e da qualidade da água etc (a depender de cada caso).

\begin{tabular}{cc}
\hline $\begin{array}{c}\text { Investimento } \\
\text { financeiro inicial } \\
\text { (pedido de } \\
\text { registro) * }\end{array}$ & $\mathrm{R} \$ 590,00$ \\
\hline Caráter & $\begin{array}{c}\text { Informativo, ou seja, indica o território do qual o } \\
\text { produto/serviço advém. }\end{array}$
\end{tabular}

$R \$ 2.135,00$
Informativo e qualitativo, ou seja, além de indicar sua origem, também aponta aspectos referentes à qualidade e/ou características do produto.

\section{Ambos são identificados por um nome geográfico que se refira ao local onde ocorre sua extração/produção/fabricação, que pode ser uma cidade, região, bairro, nome de rio, forma de relevo etc., desde que a região seja conhecida por esses nomes.}

\begin{tabular}{cc}
\hline Aplicabilidade & Produtos e serviços \\
\hline $\begin{array}{c}\text { Prazo de proteção } \\
\text { Titularidade }\end{array}$ & $\begin{array}{r}\text { Em ambos os casos é ilimitado, exceto em casos em que o nome se tornou "de uso comum" ou que } \\
\text { a IG não manteve suas características conforme caderno de especificações. }\end{array}$ \\
\hline $\begin{array}{c}\text { Veracidade de } \\
\text { procedência }\end{array}$ & A veracidade das atividades desenvolvidas no território está de acordo com a procedência exata do \\
produto/serviço em ambos os casos.
\end{tabular}

Tempo Ambas precisam estar atreladas à tradição da região, ou seja, reconhecimento e importância ao
longo do tempo.

*Valores consultados em abril de 2020, disponíveis em: <www.inpi.gov.br/arquivos/tabela-nova-ig.pdf>.

Fonte - Elaborado com base em GURGEL (2004); CERDAN (2009); BRUCH (2009); MEDEIROS e PASSADOR (2015); SEBRAE (2019); INPI (2020a).

Embora em termos de Direitos de Propriedade Industrial as IP e as DO sejam equivalentes, ou seja, não existe hierarquia ou ordem de importância entre elas (SEBRAE, 2019), em termos de complexidade, o processo de obtenção de uma IP é mais simples quanto ao cumprimento de requisitos do que uma DO. Embora os processos de requerimento sejam independentes, a entidade requerente pode se utilizar dos

$\begin{array}{llllll}\text { Caminhos de Geografia } & \text { Uberlândia-MG } & \text { v. 22, n. } 83 & \text { out./2021 } & \text { p. 47-65 } & \text { Página } 53\end{array}$


procedimentos da IP como um "preparativo" para futuramente solicitar uma DO, quando for o caso de comprovação de qualidades do produto inerentes às condições físicas e humanas locais (TRENTINI, 2006; MEDEIROS e PASSADOR, 2015).

O Instituto Nacional da Propriedade Industrial (INPI) é a entidade responsável por executar as normas que regulam a Propriedade Industrial no Brasil. As IG são regidas também pela Instrução Normativa no 095 de 28 de dezembro de 2018, que estabelece as condições para o registro das Indicações Geográficas (INPI, 2020a).

\section{BREVE PANORAMA DAS INDICAÇÕES GEOGRÁFICAS NO BRASIL}

Embora a legislação atual que versa sobre a proteção das IG seja de 1996, somente no ano de 2002 é que foi concedida a primeira IG para um produto brasileiro. A IP Vale dos Vinhedos abarca os municípios de Bento Gonçalves, Garibaldi e Monte Belo do Sul, Rio Grande do Sul, inclui os vinhos tinto, branco e espumante. O Vale dos Vinhedos é a região vitivinícola mais conhecida do país e sua reputação se deve principalmente à trajetória histórica dos imigrantes italianos provenientes de Veneto que se estabeleceram na região a partir de 1875 e desenvolveram um sistema de policultivo e pecuária, conhecida como "agricultura colonial", além da afirmação de uma identidade territorial marcada em sua produção (NIEDERLE e AGUIAR, 2012). Após a experiência obtida com o reconhecimento de IP para a região, a Associação dos Produtores de Vinhos Finos do Vale dos Vinhedos (APROVALE) em 2005 iniciou o processo de solicitação para DO, registro concedido no ano de 2012, após pesquisas nas áreas agronômica e enológica que confirmassem a excepcionalidade da região na produção de vinhos (GIESBRECHT et al., 2014). Além disso, em 2007, a região foi a primeira do Brasil a solicitar uma IG na União Europeia (GONÇALVES; ALMEIDA; BASTOS, 2018).

Vale ressaltar que antes de 2002, outras IG já tinham sido concedidas no sistema de proteção brasileiro, no entanto, referiam-se a IG não-residentes, ou seja, com origem fora do Brasil: em 1999 a DO Região dos Vinhos Verdes (Portugal) e em 2000 a DO Cognac (França) (SOUSA; MARTINEZ; SANTOS, 2019). A primeira DO concedida à produto brasileiro foi em 2010 para o arroz do Litoral Norte Gaúcho (GIESBRECHT et al., 2014).

Atualmente (última consulta em 15 de abril de 2020), foram identificadas 76 indicações geográficas vigentes no Brasil, concedidas a produtos/serviços nacionais e estrangeiros. As tabelas 3 e 4 a seguir apresentam as IP e DO concedidas entre 1999 e 2020.

Tabela 3 - Indicações de procedência concedidas no Brasil.

\begin{tabular}{|c|c|c|c|c|c|}
\hline Tipo & & Nome & Origem & Produto & $\begin{array}{l}\text { Ano de } \\
\text { registro }\end{array}$ \\
\hline Bebidas & & Vale dos Vinhedos & $\mathrm{RS}$ & Vinhos: tinto, branco e espumante & 2002 \\
\hline $\begin{array}{l}\text { Produtos } \\
\text { agrícolas } \\
\text { alimentícios }\end{array}$ & e & $\begin{array}{l}\text { Região do Cerrado } \\
\text { Mineiro }\end{array}$ & MG & Café & 2005 \\
\hline $\begin{array}{l}\text { Carnes } \\
\text { diversas } \\
\text { embutidos }\end{array}$ & e & $\begin{array}{l}\text { Pampa Gaúcho da } \\
\text { Campanha Meridional }\end{array}$ & RS & Carne bovina e derivados & 2006 \\
\hline Bebidas & & Paraty & RJ & $\begin{array}{l}\text { Produção de aguardentes, dos tipos, } \\
\text { cachaça e aguardente composta azulada }\end{array}$ & 2007 \\
\hline $\begin{array}{l}\text { Calçados } \\
\text { couro }\end{array}$ & e & Vale dos Sinos & RS & Couro acabado & 2009 \\
\hline $\begin{array}{l}\text { Produtos } \\
\text { agrícolas } \\
\text { alimentícios }\end{array}$ & e & $\begin{array}{l}\text { Vale do Submédio São } \\
\text { Francisco }\end{array}$ & $\mathrm{NE}$ & Uvas de mesa e manga & 2009 \\
\hline Bebidas & & Pinto Bandeira & $\mathrm{RS}$ & Vinhos tintos, brancos e espumantes & 2010 \\
\hline $\begin{array}{l}\text { Produtos } \\
\text { agrícolas } \\
\text { alimentícios }\end{array}$ & e & $\begin{array}{l}\text { Região da Serra da } \\
\text { Mantiqueira de Minas } \\
\text { Gerais }\end{array}$ & MG & Café & 2011 \\
\hline
\end{tabular}

$\begin{array}{lllll}\text { Caminhos de Geografia } & \text { Uberlândia-MG } & \text { v. 22, n. } 83 & \text { out./2021 } & \text { p. 47-65 }\end{array}$ Página 54




\begin{tabular}{|c|c|c|c|c|c|}
\hline $\begin{array}{l}\text { Artesanato } \\
\text { têxteis }\end{array}$ & e & $\begin{array}{l}\text { Região do Jalapão do } \\
\text { estado do Tocantins }\end{array}$ & TO & Artesanato em capim dourado & 2011 \\
\hline $\begin{array}{l}\text { Produtos } \\
\text { agrícolas } \\
\text { alimentícios }\end{array}$ & e & Pelotas & $\mathrm{RS}$ & Doces tradicionais de confeitaria e de frutas & 2011 \\
\hline $\begin{array}{l}\text { Artesanato } \\
\text { têxteis }\end{array}$ & e & Goiabeiras & ES & Panelas de barro & 2011 \\
\hline $\begin{array}{l}\text { Produtos } \\
\text { agrícolas } \\
\text { alimentícios }\end{array}$ & e & Serro & MG & Queijo minas artesanal do Serro & 2011 \\
\hline $\begin{array}{l}\text { Artesanato } \\
\text { têxteis }\end{array}$ & e & São João del-Rei & MG & Peças artesanais em estanho & 2012 \\
\hline $\begin{array}{l}\text { Calçados } \\
\text { couro }\end{array}$ & e & Franca & SP & Calçados & 2012 \\
\hline Bebidas & & Vales da Uva Goethe & SC & $\begin{array}{l}\text { Vinho branco seco, vinho branco suave ou } \\
\text { demi séc, vinho leve branco seco, vinho leve } \\
\text { branco suave ou demi séc, vinho espumante } \\
\text { brut, ou demi séc obtidos pelo método } \\
\text { "champenoise", vinho espumante brut, ou } \\
\text { demi séc obtidos pelo método "charmat", } \\
\text { vinho licoroso }\end{array}$ & 2012 \\
\hline $\begin{array}{l}\text { Produtos } \\
\text { agrícolas } \\
\text { alimentícios }\end{array}$ & e & Canastra & MG & Queijo & 2012 \\
\hline $\begin{array}{l}\text { Recursos } \\
\text { minerais }\end{array}$ & & Pedro II & $\mathrm{PI}$ & $\begin{array}{l}\text { Opala preciosa de Pedro II e joias artesanais } \\
\text { de opalas de Pedro II }\end{array}$ & 2012 \\
\hline $\begin{array}{l}\text { Recursos } \\
\text { minerais }\end{array}$ & & Cachoeiro de Itapemirim & ES & Mármore & 2012 \\
\hline $\begin{array}{l}\text { Produtos } \\
\text { agrícolas } \\
\text { alimentícios }\end{array}$ & e & $\begin{array}{lll}\text { Norte } & \text { Pioneiro } & \text { do } \\
\text { Paraná } & & \end{array}$ & PR & $\begin{array}{l}\text { Café verde em grão e industrializado torrado } \\
\text { em grão e ou moído }\end{array}$ & 2012 \\
\hline $\begin{array}{l}\text { Produtos } \\
\text { agrícolas } \\
\text { alimentícios }\end{array}$ & e & Linhares & ES & Cacau em amêndoas & 2012 \\
\hline $\begin{array}{l}\text { Artesanato } \\
\text { têxteis }\end{array}$ & e & Paraíba & PB & Têxteis de algodão natural colorido & 2012 \\
\hline Bebidas & & Região de Salinas & MG & Aguardente de cana tipo cachaça & 2012 \\
\hline Serviço & & Porto Digital & $\mathrm{PE}$ & $\begin{array}{l}\text { Serviços de tecnologia de informação e } \\
\text { comunicação através de desenvolvimento, } \\
\text { manutenção e suporte }\end{array}$ & 2012 \\
\hline Bebidas & & Altos Montes & $\mathrm{RS}$ & Vinhos e espumantes & 2012 \\
\hline $\begin{array}{l}\text { Artesanato } \\
\text { têxteis }\end{array}$ & e & Divina Pastora & SE & Renda de agulha em Lacê & 2012 \\
\hline $\begin{array}{l}\text { Produtos } \\
\text { agrícolas } \\
\text { alimentícios }\end{array}$ & e & São Tiago & MG & Biscoito & 2013 \\
\hline $\begin{array}{l}\text { Produtos } \\
\text { agrícolas } \\
\text { alimentícios }\end{array}$ & e & Alta Mogiana & SP & Café & 2013 \\
\hline $\begin{array}{l}\text { Produtos } \\
\text { agrícolas } \\
\text { alimentícios }\end{array}$ & e & Mossoró & $\mathrm{RN}$ & Melão & 2013 \\
\hline Artesanato & e & Cariri Paraibano & PB & Renda renascença & 2013 \\
\hline
\end{tabular}




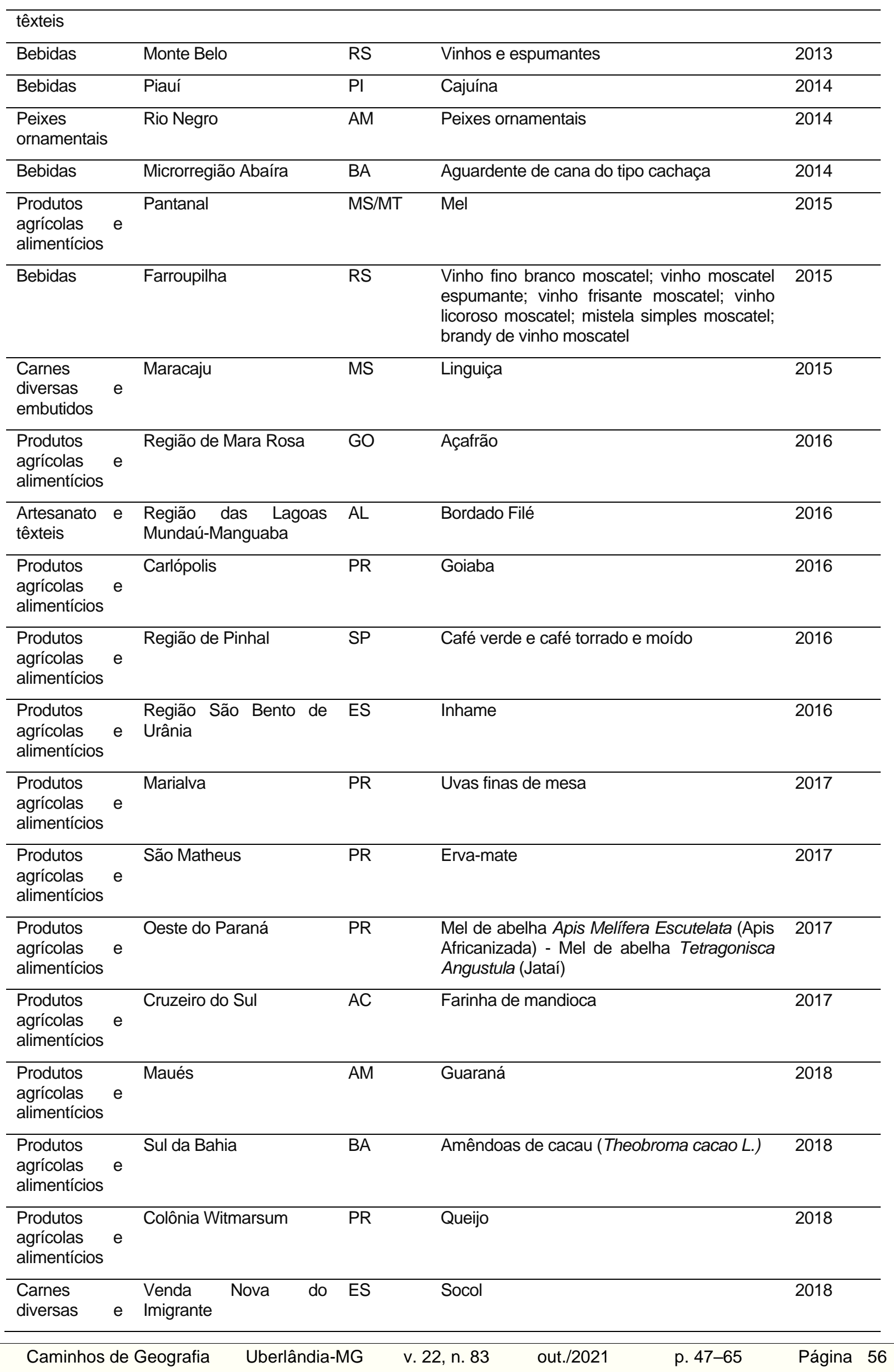




\begin{tabular}{|c|c|c|c|c|c|}
\hline embutidos & & & & & \\
\hline $\begin{array}{l}\text { Produtos } \\
\text { agrícolas } \\
\text { alimentícios }\end{array}$ & e & Sabará & MG & $\begin{array}{l}\text { Derivados de jabuticaba: licor, geleia, molho, } \\
\text { casca cristalizada e compota }\end{array}$ & 2018 \\
\hline $\begin{array}{l}\text { Produtos } \\
\text { agrícolas } \\
\text { alimentícios }\end{array}$ & e & Tomé-Açu & PA & Cacau & 2019 \\
\hline $\begin{array}{l}\text { Produtos } \\
\text { agrícolas } \\
\text { alimentícios }\end{array}$ & e & Oeste da Bahia & BA & $\begin{array}{l}\text { Café verde em grãos, da espécie Coffea } \\
\text { arábica }\end{array}$ & 2019 \\
\hline $\begin{array}{l}\text { Artesanato } \\
\text { têxteis }\end{array}$ & e & Pirenópolis & GO & Joias artesanais em prata & 2019 \\
\hline $\begin{array}{l}\text { Produtos } \\
\text { agrícolas } \\
\text { alimentícios }\end{array}$ & e & Uarini & AM & Farinha de mandioca & 2019 \\
\hline $\begin{array}{l}\text { Produtos } \\
\text { agrícolas } \\
\text { alimentícios }\end{array}$ & e & Capanema & PR & Melado batido e melado escorrido & 2019 \\
\hline
\end{tabular}

Fonte - Elaborado com base em dados obtidos no site do INPI (2020b).

Tabela 4 - Denominações de origem nacionais e estrangeiras concedidas no Brasil.

\begin{tabular}{|c|c|c|c|c|}
\hline Tipo & Nome & Origem & Produto & $\begin{array}{l}\text { Ano de } \\
\text { registro }\end{array}$ \\
\hline Bebidas & $\begin{array}{l}\text { Região dos Vinhos } \\
\text { Verdes }\end{array}$ & Portugal & Vinhos & 1999 \\
\hline Bebidas & Cognac & França & Destilado vínico ou aguardente de vinho & 2000 \\
\hline Bebidas & Franciacorta & Itália & $\begin{array}{l}\text { Vinhos, vinhos espumantes e bebidas } \\
\text { alcoólicas }\end{array}$ & 2003 \\
\hline $\begin{array}{l}\text { Carnes } \\
\text { diversas e } \\
\text { embutidos }\end{array}$ & San Daniele & Itália & $\begin{array}{l}\text { Coxas de suínos frescas, presunto defumado } \\
\text { e cru }\end{array}$ & 2009 \\
\hline $\begin{array}{l}\text { Produtos } \\
\text { agrícolas e } \\
\text { alimentícios }\end{array}$ & Litoral Norte Gaúcho & $\mathrm{RS}$ & Arroz & 2010 \\
\hline $\begin{array}{l}\text { Carnes } \\
\text { diversas e } \\
\text { embutidos }\end{array}$ & Costa Negra & $\mathrm{CE}$ & $\begin{array}{l}\text { Camarões marinhos cultivados da espécie } \\
\text { Litopenaeus vanname }\end{array}$ & 2011 \\
\hline Bebidas & Porto & Portugal & Vinho generoso (vinho licoroso) & 2012 \\
\hline $\begin{array}{l}\text { Recursos } \\
\text { minerais }\end{array}$ & $\begin{array}{l}\text { Região Pedra Carijó Rio } \\
\text { de Janeiro }\end{array}$ & RJ & $\begin{array}{l}\text { Gnaisse fitado milonítico de coloração } \\
\text { branca e pontos vermelhos }\end{array}$ & 2012 \\
\hline $\begin{array}{l}\text { Recursos } \\
\text { minerais }\end{array}$ & $\begin{array}{l}\text { Região Pedra Madeira } \\
\text { Rio de Janeiro }\end{array}$ & RJ & $\begin{array}{c}\text { Gnaisse fitado milonítico de coloração clara } \\
\text { com quatro variedades de cor: branca, rosa, } \\
\text { verde e amarela }\end{array}$ & 2012 \\
\hline $\begin{array}{l}\text { Recursos } \\
\text { minerais }\end{array}$ & $\begin{array}{l}\text { Região Pedra Cinza Rio } \\
\text { de Janeiro }\end{array}$ & RJ & Gnaisse fitado milonítico de coloração cinza & 2012 \\
\hline $\begin{array}{l}\text { Produtos } \\
\text { agrícolas e } \\
\text { alimentícios }\end{array}$ & Manguezais de Alagoas & $\mathrm{AL}$ & $\begin{array}{c}\text { Própolis vermelha e extrato de própolis } \\
\text { vermelha }\end{array}$ & 2012 \\
\hline Bebidas & Napa Valley & $\begin{array}{l}\text { Estados } \\
\text { Unidos }\end{array}$ & Vinhos & 2012 \\
\hline Bebidas & Vale dos Vinhedos & RS & Vinhos e espumantes & 2012 \\
\hline
\end{tabular}




\begin{tabular}{|c|c|c|c|c|}
\hline Bebidas & Champagne & França & Vinhos e espumantes & 2012 \\
\hline $\begin{array}{l}\text { Produtos } \\
\text { agrícolas e } \\
\text { alimentícios }\end{array}$ & Roquefort & França & Queijo & 2013 \\
\hline $\begin{array}{c}\text { Produtos } \\
\text { agrícolas e } \\
\text { alimentícios }\end{array}$ & $\begin{array}{l}\text { Região do Cerrado } \\
\text { Mineiro }\end{array}$ & MG & $\begin{array}{c}\text { Café verde em grão e café industrializado } \\
\text { torrado em grão ou moído }\end{array}$ & 2013 \\
\hline $\begin{array}{c}\text { Produtos } \\
\text { agrícolas e } \\
\text { alimentícios }\end{array}$ & Ortigueira & PR & Mel de abelha - Apis mellífera & 2015 \\
\hline $\begin{array}{c}\text { Produtos } \\
\text { agrícolas e } \\
\text { alimentícios }\end{array}$ & $\begin{array}{c}\text { Região da Própolis } \\
\text { Verde de Minas Gerais }\end{array}$ & MG & Própolis verde & 2016 \\
\hline $\begin{array}{c}\text { Produtos } \\
\text { agrícolas e } \\
\text { alimentícios }\end{array}$ & $\begin{array}{l}\text { Banana da Região de } \\
\text { Corupá }\end{array}$ & SC & Banana (subgrupo Cavendish) & 2018 \\
\hline Bebidas & Tequila & México & $\begin{array}{c}\text { Destilado de agave tequilana weber de } \\
\text { variedade azul }\end{array}$ & 2019 \\
\hline $\begin{array}{c}\text { Produtos } \\
\text { agrícolas e } \\
\text { alimentícios }\end{array}$ & $\begin{array}{l}\text { Campos de Cima da } \\
\text { Serra }\end{array}$ & $\mathrm{SC} / \mathrm{RS}$ & Queijo artesanal Serrano & 2020 \\
\hline
\end{tabular}

Fonte - Elaborado com base em dados obtidos no site do INPI (2020b).

Conforme dados das tabelas apresentadas, das 76 IG, 55 caracterizam-se como IP e 21 como DO (destas, 12 são nacionais e nove estrangeiras, sendo três francesas, duas portuguesas, duas italianas, uma mexicana e uma estadunidense). Embora pouco expressiva no volume de IG concedidas, a busca de outros países por reconhecer suas DO no Brasil (cujas qualidades já eram reconhecidas nos países de origem) pode ser um indicativo de que o país é cotado "[...] não apenas por sua localização estratégica na América Latina, e posição no cenário econômico mundial, mas também pelo crescimento de seu mercado consumidor cada vez mais exigente e admirador de grandes rótulos, sobretudo aqueles de reconhecida qualidade" (BRITO, 2015, s/p).

Das 55 IP brasileiras, 51\% enquadram-se em produtos agrícolas e alimentícios em geral (como frutas, cafés, queijos, doces, mel etc.) e $18 \%$ em bebidas (predominantemente vinhos) (figura 1). Já no caso das $\mathrm{DO}, 38 \%$ enquadram-se em produtos agrícolas e alimentícios em geral e $38 \%$ em bebidas (figura 2). Entre os produtos agrícolas e alimentícios com IG o que mais se destaca é o café, com seis IP e uma DO. Já entre as bebidas, 0 vinho se sobressai, com seis IP e seis DO (sendo uma brasileira e quatro estrangeiras). Destaca-se que, até o momento, há apenas um serviço reconhecido com IP no Brasil, ligado a serviços de tecnologia da informação (TI) em Pernambuco.

Figura 1 - Tipo de produto/serviço com Indicação de Procedência.

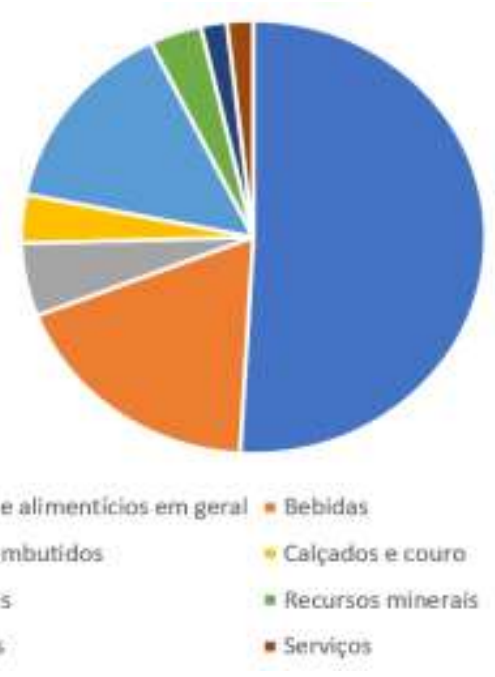

Fonte - Elaborado com base em dados obtidos no site do INPI (2020b).

$\begin{array}{llllll}\text { Caminhos de Geografia } & \text { Uberlândia-MG } & \text { v. 22, n. } 83 & \text { out./2021 } & \text { p. 47-65 } & \text { Página } 58\end{array}$


Figura 2 - Tipo de produto com Denominação de Origem.

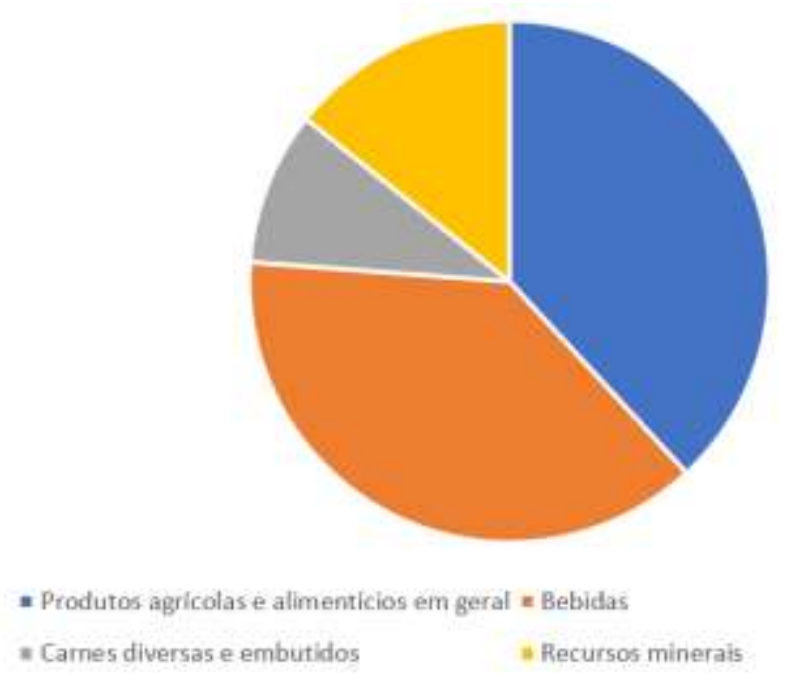

Fonte - Elaborado com base em dados obtidos no site do INPI (2020b).

A região do Brasil que apresenta maior quantidade de IG é o Sudeste, com 22, seguido pela região Sul, com 21 e percebe-se um escasso número de IG concedidas nas regiões Norte (6) e Centro-Oeste (4) (figura 3). Os estados que mais apresentam IG são Rio Grande do Sul (10), Minas Gerais (10) e Paraná (8). Apenas os estados de Amapá, Maranhão, Roraima e Rondônia ainda não apresentam nenhuma IG concedida. Uma das explicações é que provavelmente há ainda falta de informação sobre a IG e suas vantagens (no caso das regiões com poucas IG concedidas) e o destaque para Sul e Sudeste devido aos convênios estabelecidos entre o INPI e o Ministério da Agricultura, Pecuária e Abastecimento (MAPA) que tinham como objetivo a exportação (NASCIMENTO et al., 2012). Carvalho e Dias (2012, p. 370), a respeito da concentração de IG no Rio Grande do Sul e Minas Gerais, "[...] sugere inferências que vinculem esta trajetória à influência europeia no tocante ao registro de produtos como vinhos e queijos, dentre outros".

Figura 3 - Quantidade de indicações geográficas por região.

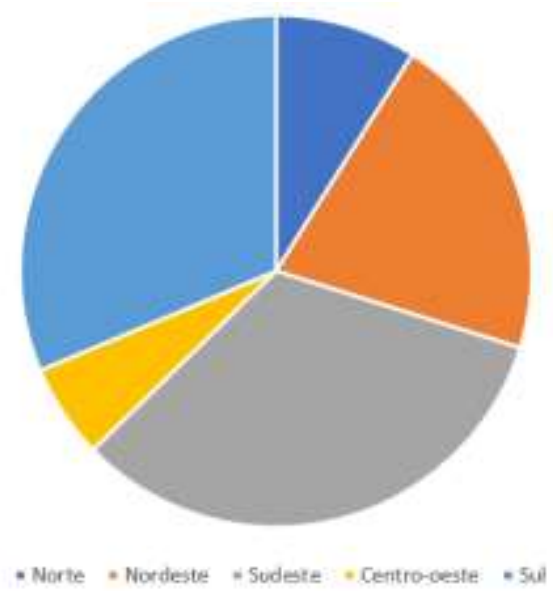

Fonte - Elaborado com base em dados obtidos no site do INPI (2020b).

Apesar do crescimento na quantidade de IG concedidas nos últimos anos no país, ainda é inexpressiva frente a grande sociobiodiversidade brasileira. Este crescimento pode estar relacionado tanto ao maior conhecimento por parte dos produtores, quanto pela necessidade de diferenciação frente à competitividade nos mercados, como também devido à divulgação e implementação de políticas públicas desenvolvidas por órgãos como o MAPA e o INPI (DRUZIAN e NUNES, 2012; VALENTE et al., 2012; GONÇALVES; ALMEIDA; BASTOS, 2018).

$\begin{array}{llllll}\text { Caminhos de Geografia } & \text { Uberlândia-MG } & \text { v. 22, n. } 83 & \text { out./2021 } & \text { p. 47-65 } & \text { Página } 59\end{array}$


Para fomentar, sensibilizar e implementar as IG no país, estes órgãos trabalham em parceria com várias instituições, como o Serviço Brasileiro de Apoio às Micro e Pequenas Empresas (SEBRAE), a Empresa Brasileira de Pesquisa Agropecuária (EMBRAPA), centros de pesquisa vinculados às universidades, entre outras (MEDEIROS e PASSADOR, 2015).

Gurgel (2004) salienta que a baixa demanda por registros desta ordem ocorre normalmente em países em desenvolvimento, pois em países desenvolvidos já é uma ferramenta de competitividade econômica, pois "[...] possuem incentivos e mediação desse processo organizacional pelo poder público em parceria com organizações locais ou regionais, por ser um importante vetor de política pública territorial, empoderamento e de identidade cultural [...] (p. 47)".

Ainda que, até o momento, o aspecto econômico das IG tenha sido salientado, há inúmeras outras questões que envolvem a proteção de produtos e serviços e que são amplamente importantes em diferentes contextos. Embora tenham sido criadas inicialmente para fins comerciais, as IG se tornaram instrumentos para diversos fins, como os propósitos de desenvolvimento rural, conservação cultural e ambiental etc. (SAUTIER; BIÉNABE; CERDAN, 2011). A tabela 4 a seguir apresenta uma síntese das possibilidades de benefícios proporcionados pelas IG, de acordo com a visão de diferentes autores a partir de estudos que retratam realidades diversas:

Tabela 4 - Benefícios proporcionados pelas Indicações Geográficas.

\begin{tabular}{|c|c|c|}
\hline $\begin{array}{c}\text { Aspectos econômicos, mercadológicos e do } \\
\text { desenvolvimento local }\end{array}$ & dos à & $\begin{array}{l}\text { Aspectos culturais e } \\
\text { ambientais }\end{array}$ \\
\hline $\begin{array}{l}\text { Assegura a qualidade e identidade destes produtos } \\
\text { registrados; } \\
\text { Estimula a melhoria qualitativa de produtos e serviços; } \\
\text { Contribui como estratégia para fortalecer o território com o } \\
\text { desenvolvimento de novos produtos e serviços ligados direta e } \\
\text { indiretamente à cadeia produtiva, como hospedagem, turismo, } \\
\text { gastronomia, artesanato etc.; } \\
\text { Facilita o acesso a crédito; } \\
\text { Promoção da região, atribuindo uma imagem positivo ao lugar; } \\
\text { Atua como um organizador do processo produtivo local; }\end{array}$ & $\begin{array}{l}\text { Protege o uso, por parte } \\
\text { dos produtores, de sua } \\
\text { identificação nominal e } \\
\text { seu ativo intangível; } \\
\text { Atua contra fraudes e } \\
\text { imitações comerciais; } \\
\text { Garante a } \\
\text { rastreabilidade do } \\
\text { produto, pelo } \\
\text { conhecimento de sua } \\
\text { origem e de toda a } \\
\text { cadeia produtiva; } \\
\text { Estabelece } \\
\text { minimamente um padrão } \\
\text { de produção; }\end{array}$ & $\begin{array}{l}\text { Oportuniza a revalorização } \\
\text { das tradições, dos saberes } \\
\text { locais, afirmando a } \\
\text { identidade territorial; } \\
\text { Protege o patrimônio } \\
\text { cultural (material e } \\
\text { imaterial); } \\
\text { Conservação ambiental a } \\
\text { partir da definição de regras } \\
\text { de produção. }\end{array}$ \\
\hline
\end{tabular}

Incrementa a renda dos produtores;

Estimula a criação de novos empregos;

Incentiva o aumento do valor das terras e imóveis da região;

Podem manter e revitalizar pequenas cidades e áreas rurais desfavorecidas;

Diminui o êxodo rural;

Estimula a coesão social, por meio da criação e fortalecimento de parcerias;

Capacitação profissional da população local.

Fonte - Elaborado com base em CALDAS; CERQUEIRA; PERIN (2005); DIAS (2005); BRUCH (2008); DULLIUS FROEHLICH; VENDRUSCOLO (2008); VELLOSO (2008); CERDAN (2009); NIEDERLE (2009, 2015); KRONE e MENASCHE (2009, 2010); ALMEIDA; PAIVA JUNIOR; GUERRA (2010); VITROLLES (2011); NEIVA; SERENO; FIORAVANTI (2011); SAUTIER; BIÉNABE; CERDAN (2011); NASCIMENTO; NUNES; BANDEIRA (2012);

CARVALHO e DIAS (2012); VIEIRA; WATANABE; BRUNCH (2012); NASCIMENTO et al. (2012); VALENTE; PEREZ; FERNANDES (2013); PIMENTEL (2014); SANTOS e MENASCHE (2015); MEDEIROS (2015); MEDEIROS e PASSADOR (2015); PEREIRA; LOURENZANI; WATANABE (2018).

$\begin{array}{lllll}\text { Caminhos de Geografia } & \text { Uberlândia-MG } & \text { v. 22, n. } 83 & \text { out./2021 } & \text { p. 47-65 }\end{array}$ Página 60


Mesmo diante de inúmeros benefícios que as IG podem proporcionar, é importante salientar que "[...] o registro de uma IG, por si só, não garante a priori um sucesso comercial determinado" (PIMENTEL, 2014, p. 45), nem tampouco a concretização de outros benefícios. É necessário que produtores e entidades representativas se articulem internamente e também que haja apoio institucional, com políticas públicas voltadas para a promoção das IG no Brasil. A articulação também é necessária para que não se torne um instrumento de exclusão e desigualdade entre os membros da cadeia produtiva e a comunidade local.

O empenho e motivação dos atores locais na implementação de uma IG é outro aspecto que precisa ser fortalecido [...]. Não somente o protagonismo deve ser estimulado, mas também deve ser desenvolvida uma consciência de construção e retorno de longo prazo, de modo que o processo de reconhecimento da IG seja realizado de forma ordenada, consistente e focada em resultados futuros, e não imediatos, sob risco de frustração dos atores envolvidos (VALENTE et al., 2012, p. 557).

É salutar o conhecimento destes benefícios, no entanto, existem riscos e efeitos negativos que podem vir a partir de condutas equivocadas quanto à gestão das IG, como por exemplo, a sobre-exploração das terras para sustentar o aumento da demanda por estes produtos, a descaracterização de produtos tradicionais quando se estabelece a padronização da produção etc.

\section{CONSIDERAÇÕES FINAIS}

Esta pesquisa pretendeu expressar como o processo de registro das indicações geográficas pode contribuir para a valorização dos atributos territoriais de produtos alimentares. Para isso, traçou um breve histórico de surgimento das indicações geográficas, sobretudo no contexto europeu, para então apresentar um panorama atual das indicações geográficas brasileiras, resgatando seu histórico e delineando suas características, benefícios e os produtos e serviços certificados até o mês de abril de 2020, relacionando então como as certificações e outras formas de reconhecimento são importantes para a valorização de produtos alimentares, não apenas no sentido econômico, mas também cultural e ambiental.

Entende-se que este sistema legal de proteção à propriedade intelectual, embora não seja novo no sentido cronológico do termo, mesmo que nos últimos 10 anos tenha obtido maior crescimento, ainda necessita ser mais divulgado tanto aos produtores, para que saibam o que existe de possibilidades para valorização de seus produtos, quanto para os consumidores, de forma que compreendam a relevância e o diferencial que produtos/serviços com IG apresentam frente a outros no mercado.

A realidade brasileira e de outros países latino-americanos não se compara à longevidade com que as IG têm na Europa, em que os países têm tradição em buscar certificações, selos e outras formas de reconhecimento de seus produtos. Todavia, já existem discussões em âmbito europeu quanto a atual validade das IG, já que, segundo alguns, se popularizaram e disseminaram de tal forma que em alguns lugares já não é mais sinônimo de diferencial e há debates quanto aos ajustes e inovações quanto a legislação vigente. No Brasil também seria relevante uma revisão na Lei de Propriedade Intelectual, lei $n^{\circ}$ 9.279 instituída em 14 de maio de 1996 e que a Instrução Normativa oo 095 de 28 de dezembro de 2018 contemplasse outros aspectos, como os referentes às questões de responsabilidade socioambiental e conservação histórico-cultural.

Como principais contribuições da pesquisa estão a apresentação de um panorama geral das indicações geográficas brasileiras, assim como suas características e possíveis benefícios, além de buscar estimular os estudos geográficos sobre o tema pela comunidade acadêmica. Assim, vislumbra-se que, como sugestão para futuros estudos referentes ao tema, sejam contempladas pesquisas que tracem uma análise comparativa de produtos de categorias semelhantes, como os cafés, vinhos, artesanato, entre outros, quanto aos benefícios proporcionados pelo reconhecimento como indicação geográfica, sobretudo no que concerne aos atributos territoriais que promovam a valorização dos produtos.

\section{AGRADECIMENTOS}

O presente trabalho foi realizado com apoio da Coordenação de Aperfeiçoamento de Pessoal de Nível Superior - Brasil (CAPES) sob supervisão da professora Dra. Silvana do Rocio de Souza.

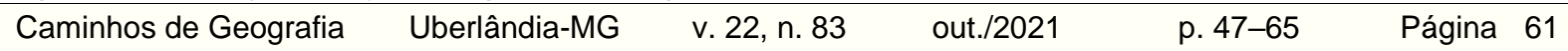




\section{REFERÊNCIAS}

ACORDO histórico protegerá 100 indicações geográficas europeias na China. Comissão Europeia, 6 de novembro de 2019. Disponível em: <https://ec.europa.eu/commission/presscorner/detail/pt/IP_19_6200>. Acesso em: 11 de abril de 2020.

ARIPO - AFRICA REGIONAL INTELLECTUAL PROPERTY ORGANIZATION. Traditional Knowledge. Disponível em: <www.aripo.org/ip-services/traditional-knowledge/>. Acesso em: 13 de abril de 2020.

ALMEIDA, F. S. de. Comércio ético e solidário: mercado livre e desenvolvimento na prática. In: LAGES, V.; LAGARES, L.; BRAGA, C. L. (Orgs.). Valorização de produtos com diferencial de qualidade e identidade: indicações geográficas e certificações para competitividade nos negócios. Brasília: Sebrae, 2005. p. 205-232.

ALMEIDA, S. de L.; PAIVA JUNIOR, F. G. de; GUERRA, J. R. F. A estratégia de internacionalização de negócios na perspectiva da tradução cultural: o caso da indicação geográfica no agronegócio. Revista Ibero-Americana de Estratégia - RIAE, São Paulo, v. 9, n. 2, p. 75-98, mai./ago. 2010. https://doi.org/10.5585/riae.v9i2.1670

ALTAMANN, R. Certificação de qualidade e origem e desenvolvimento rural. In: LAGES, V.; LAGARES, L.; BRAGA, C. L. (Orgs.). Valorização de produtos com diferencial de qualidade e identidade: indicações geográficas e certificações para competitividade nos negócios. Brasília: SEBRAE, 2005. p.133-140.

APROVALE - ASSOCIAÇÃO DOS PRODUTORES DE VINHOS FINOS DO VALE DOS VINHEDOS. Disponível em: <www.valedosvinhedos.com.br/vale/index.php>. Acesso em: 15 de abril de 2020.

AZEVEDO, E. de. O ativismo alimentar na perspectiva do locavorismo. Ambiente \& Sociedade, São Paulo, v. 18, n. 3, p. 81-98, jul./set. 2015. https://doi.org/10.1590/1809-4422ASOC740V1832015

BARROS, A. F. G.; VARELLA, M. D. A nova tendência mundial de segurança alimentar e o sistema de certificações. In: LAGES, V.; BRAGA, C.; MORELLI, G. (Orgs.). Territórios em movimento: cultura e identidade como estratégia de inserção competitiva. Rio de Janeiro: Relume Dumará/ Brasília: SEBRAE, 2004. p. 201-218.

BERTOZZI, L. Designations of origin: quality and specification. Food Quality and Preferences, v.6, n. 3, p.143-147, 1995. https://doi.org/10.1016/0950-3293(95)00013-Y

BOLFE, É. Uma oportunidade chamada Indicação Geográfica. Embrapa, 1 de abril de 2019. Disponível em: <www.embrapa.br/busca-de-noticias/-/noticia/42340794/artigo---uma-oportunidade-chamadaindicacao-geografica>. Acesso em: 11 de abril de 2020.

BRABET, C.; PALLET, D. Os selos oficiais de qualidade dos alimentos na França e na Europa. In: LAGES, V.; LAGARES, L.; BRAGA, C. L. (Orgs.). Valorização de produtos com diferencial de qualidade e identidade: indicações geográficas e certificações para competitividade nos negócios. Brasília: SEBRAE, 2005. p.19-43.

BRASIL. Lei $\mathrm{n}^{\circ}$ 9.279, de 14 de maio de 1996. Disponível em: $<w w w . p l a n a l t o . g o v . b r / c c i v i l[03 / L e i s / L 9279 . h t m>$. Acesso em: 13 de abril de 2020.

BRITO, A. P. A. Registro de indicações geográficas no Brasil. Alfonsin, 11 de junho de 2015. Disponível em: <http://alfonsin.com.br/registro-de-indicaes-geogrficas-no-brasil/>. Acesso em: 15 de abril de 2020.

BRUCH, K. L. Tradição e cultura preservadas: Indicações Geográficas são meio para assegurar reconhecimento aos diferenciais de uma região produtora. Jornal Bon Vivant, Flores da Cunha, p. 12, jan./fev. 2009.

CALDAS, A. dos S.; CERQUEIRA, P. da S.; PERIN, T. de F. Mais além dos arranjos produtivos locais: as indicações geográficas protegidas como unidades de desenvolvimento local. Revista de Desenvolvimento Econômico, Salvador, ano 7, n. 11, p. 5-16, jan. 2005.

CALDAS, A. dos S. As denominações de origem como unidade de planejamento, desenvolvimento local e inclusão social. Revista de Desenvolvimento Econômico, Salvador, v. 5, n. 8, p. 25-32, 2003.

CALLIARI, M. A.; BUAINAIN, A. M.; CARVALHO, S. M. P. de; CHAMAS, C. I.; SALLES-FILHO, S. L. M.; SILVEIRA, J. M. F. J. da. Proteção às Indicações Geográficas: A Experiência Brasileira. In: SEMINARIO LATINO-IBEROAMERICANO DE GESTIÓN TECNOLÓGICA, 12., 2007, Buenos Aires. Anais... Buenos Aires: Asociación Latino Iberoamericana de Gestión Tecnológica, 2007. 
CARVALHO, G. dos R.; DIAS, A. B. Indicação geográfica no território do sisal na Bahia: possibilidades e perspectivas. Revista Geintec, v. 2, n. 4, p. 365-377, 2012. https://doi.org/10.7198/S2237$\underline{0722201200040004}$

CERDAN, C. Valorização dos produtos de origem e do patrimônio dos territórios rurais no sul do Brasil: Contribuição para o desenvolvimento territorial sustentável. Política \& Sociedade, v.8, n.14, p. 277-299, 2009. https://doi.org/10.5007/2175-7984.2009v8n14p277

DIAS, J. F. D. V. da R. A construção institucional da qualidade em produtos tradicionais. Dissertação (Mestrado em Desenvolvimento, Agricultura e Sociedade) - Rio de Janeiro: UFRRJ, 2005.

DULLIUS, P. R.; FROEHLICH, J. M.; VENDRUSCOLO, R. Identidade e desenvolvimento territorial estudo das experiências de indicações geográficas no estado do RS. In: CONGRESSO DA SOCIEDADE BRASILEIRA DE ECONOMIA, ADMINISTRAÇÃO E SOCIOLOGIA RURAL, 46., 2008, Rio Branco. Anais... Rio Branco: Sociedade Brasileira de Economia, Administração e Sociologia Rural, 2008.

DRUZIAN, J. I.; NUNES, I. L. Indicações Geográficas Brasileiras e Impacto sobre Bens Agrícolas e/ou agroindustriais. Revista Geintec, v. 2, n. 4, p. 413-426, 2012.

EUROPEAN COMMISSION. Quality schemes explained. Disponível em: <https://ec.europa.eu/info/foodfarming-fisheries/food-safety-and-quality/certification/quality-labels/quality-schemesexplained_en\#geographicalindications>. Acesso em: 11 de abril de 2020.

FAO - FOOD AND AGRICULTURE ORGANIZATION OF THE UNITED NATIONS. O que é a agricultura familiar. Disponível em: <www.fao.org/family-farming/detail/en/c/454156/>. Acesso em: 9 de abril de 2020.

GIESBRECHT, H. O.; MINAS, R. B. A. de; GONÇALVES, M. F. W.; SCHWANKE, F. H. Indicações geográficas brasileiras. Brasília: Sebrae, INPI, 2014.

GONÇALVES, L. A. da S.; ALMEIDA, B. de A.; BASTOS, E. M. S. Panorama das indicações geográficas no Brasil. Revista de Desenvolvimento Econômico, Salvador, ano 20, v. 3, n. 41, p. 130-144, dez. 2018.

GURGEL, V. A. Aspectos jurídicos da indicação geográfica. In: LAGES, V.; BRAGA, C.; MORELLI, G. (Orgs.). Territórios em movimento: cultura e identidade como estratégia de inserção competitiva. Rio de Janeiro: Relume Dumará/ Brasília: SEBRAE, 2004. p. 44-58.

ÍNDIA. Intelectual Property Índia - Geographical Indications Registry. Disponível em: $<w w w . j p i n d i a . n i c . i n / r e g i s t e r e d-g l s . h t m>$. Acesso em: 11 de abril de 2020.

INPI - INSTITUTO NACIONAL DE PROPRIEDADE INDUSTRIAL. Instrução Normativa no 095 de $\mathbf{2 8}$ de dezembro de 2018. Disponível em: <www.inpi.gov.br/menu-servicos/indicacao-geografica/legislacaoindicacao-geografica-1>. Acesso em: 13 de abril de 2020a.

Pedidos de indicação geográfica concedidos e em andamento. Disponível em:

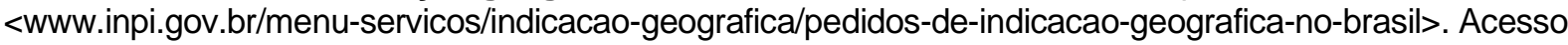
em: 15 abr. 2020b.

KRONE, E.; MENASCHE, R. Políticas públicas para produtos com identidade cultural: uma reflexão a partir do caso do Queijo Artesanal Serrano do sul do Brasil. In: CONGRESSO LATINO-AMERICANO DE SOCIOLOGIA RURAL, 8., 2010, Porto de Galinhas. Anais... Porto de Galinhas (PE): Alasru, 2010.

A diversidade como elemento de diferenciação de produtos artesanais: o caso do Queijo Artesanal Serrano dos Campos de Cima da Serra (RS). In: ENCONTRO ACADÊMICO DE PROPRIEDADE INTELECTUAL, INOVAÇÃO E DESENVOLVIMENTO, 2., 2009, Rio de Janeiro. Anais... Rio de Janeiro: INPI, 2009.

KRÜCKEN-PEREIRA, L. O processo de valorização de produtos alimentícios através das denominações de origem e qualidade: uma abordagem de gestão do conhecimento. Dissertação (Mestrado em Engenharia de Produção) - Florianópolis: UFSC, 2001.

LIMA, F. D.; GIESBRECHT, H. O.; LIMA, S. U. de. Indicação geográfica: agregação de valor aos produtos amazônicos. T\&C Amazônia, ano V, n.11, p.42-48, 2007.

LIPOVETSKY, G. A felicidade paradoxal: ensaios sobre a sociedade de hiperconsumo. Trad. Maria Lúcia Machado. São Paulo: Companhia das Letras, 2007. 
LOPES, P. R.; LOPES, K. C. S. A. Sistemas de produção de base ecológica - a busca por um desenvolvimento rural sustentável. REDD - Revista Espaço de Diálogo e Desconexão, Araraquara, v. 4, n. 1, p. 1-32, jul./dez. 2011.

MARIOT, E. J. Produtos agroalimentares típicos (coloniais): situação e perspectivas de valorização no município de Urussanga, Santa Catarina, Brasil. Dissertação (Mestrado Internacional em Gestão do Desenvolvimento Rural) - Vila Real, Portugal: Universidade de Trás-os-Montes e Alto Douro/Universidade de Santiago de Compostela, 2002.

MEDEIROS, M. de L. Indicações geográficas, turismo e desenvolvimento territorial: uma análise sistêmica da indicação de procedência do queijo minas artesanal do Serro. Tese (Doutorado em Administração de Organizações) - Ribeirão Preto: USP, 2015.

MEDEIROS, M. de L.; PASSADOR, J. L. Indicações geográficas e turismo: possibilidades no contexto brasileiro. Perspectivas Contemporâneas, v. 10, n. 3, p. 56-79, set./dez. 2015.

NASCIMENTO, J. S.; NUNES, G. S.; FIALHO, A. S.; BANDEIRA, M. da G. A. Indicações geográficas: agregação de valor aos produtos brasileiros e maranhenses. Revista Geintec, v. 2, n. 4, p. 353-364, 2012.

NASCIMENTO, J. S.; NUNES, G. S.; BANDEIRA, M. da G. A. A importância de uma indicação geográfica no desenvolvimento do turismo de uma região. Revista Geintec, v. 2, n. 4, p. 378-386, 2012. https://doi.org/10.7198/S2237-0722201200040005

NEIVA, A. C. G.; SERENO, J. R. B.; FIORAVANTI, M. C. S. Indicação Geográfica na conservação e agregação de valor ao gado curraleiro da comunidade Kalunga. Arch. Zootec, v. 60, n. 231, p. 357-360, 2011. https://doi.org/10.4321/S0004-05922011000300010

NIEDERLE, P. A. A institucionalização de um mercado para produtos com Indicações Geográficas no Brasil: uma abordagem sociológica. In: VIEIRA, A. C. P.; BRUCH, K. L. (Orgs.). Indicação geográfica, signos coletivos e desenvolvimento. IBPI Europa, 2015.

Controvérsias sobre a noção de indicações geográficas enquanto instrumento de desenvolvimento territorial: a experiência do Vale dos Vinhedos em questão. In: CONGRESSO BRASILEIRO DE ECONOMIA, ADMINISTRAÇÃO E SOCIOLOGIA RURAL, 47., 2009, Porto Alegre. Anais... Porto Alegre: SOBER, 2009.

NIEDERLE, P. A.; AGUIAR, M. Indicações geográficas, tipicidade e produtos localizados: os novos compromissos valorativos na vitivinicultura do Vale dos Vinhedos. Revista de Economia Agrícola, São Paulo, v. 59, n. 2, p. 21-37, jul./dez. 2012.

PEREIRA, M. E. B. de G.; LOURENZANI, A. E. B. S.; WATANABE, K. Indicações Geográficas como estratégia de desenvolvimento: o caso do Norte Pioneiro do Paraná. Interações, Campo Grande, v. 19, n. 3, p. 515-528, jul./set. 2018. https://doi.org/10.20435/inter.v19i3.1654

PIMENTEL, L. O. (Org.). Curso de propriedade intelectual \& inovação no agronegócio: Módulo II, indicação geográfica. 4. ed. Florianópolis: MAPA/FUNJAB, 2014.

POULAIN, J. Sociologias da alimentação: os comedores e o espaço social alimentar. Florianópolis: EDUFSC, 2004.

SANTOS, J. S.; MENASCHE, R. Valorização de produtos alimentares tradicionais: os usos das indicações geográficas no contexto brasileiro. Cuadernos de Desarrollo Rural, Bogotá (Colômbia), v. 12, n. 75, p. 11-31, jan./jun. 2015. https://doi.org/10.11144/Javeriana.cdr12-75.vpat

SAUTIER, D.; BIÉNABE, E.; CERDAN, C. Geographical Indications in Developing Countries. In: BARHAM, E.; SYLVANDER, B. (Eds.). Labels of origin for food: local development, global recognition. Oxfordshire: CABI, 2011. p. 138-153. https://doi.org/10.1079/9781845933524.0138

SEBRAE - SERVIÇO BRASILEIRO DE APOIO ÀS MICRO E PEQUENAS EMPRESAS. Guia das indicações geográficas: conceitos. 2019. Disponível em:

<https://datasebrae.com.br/indicacoesgeograficas/>. Acesso em: 17 de abril de 2020.

SLOW Food Brasil. Disponível em: <www.slowfoodbrasil.com/slowfood/o-movimento>. Acesso em: 9 de abril de 2020. 
SOUSA, L. M.; MARTINEZ, M. E. M.; SANTOS, M. J. C. dos. Panorama das indicações geográficas vigentes no Brasil. Revista INGI - Indicação Geográfica e Inovação, v. 3, n. 3, p. 378-389, jul./ago./set. 2019.

TRENTINI, F. Denominação de Origem: elemento fundamental às atuais empresas rurais. Tese (Doutorado em Direito) - São Paulo: USP, 2006.

VALENTE, M. E. R.; PEREZ, R.; FERNANDES, L. R. R. de M. V. O processo de reconhecimento das indicações geográficas de alimentos e bebidas brasileiras: regulamento de uso, delimitação da área e diferenciação do produto. Ciência Rural, v. 43, n. 7, p. 1330-1336, 2013.

https://doi.org/10.1590/S0103-84782013005000076

VALENTE, M. E. R.; PEREZ, R.; RAMOS, A. M.; CHAVES, J. B. P. Indicação geográfica de alimentos e bebidas no Brasil e na União Europeia. Ciência Rural, v. 42, n. 3, p. 551-558, 2012.

https://doi.org/10.1590/S0103-84782012000300027

VARGAS-CHAVES, I. Los conocimientos tradicionales y sus escenarios de articulación con el comercio y el ambiente. In: SÁENZ A.; GÓMEZ A.; RODRíGUEZ, G. (Eds.). Conflictos entre Propiedad, Comercio y Ambiente. Bogotá: Grupo Editorial lbáñez, 2014. p. 315-334. https://doi.org/10.2139/ssrn.2742500

VELLOSO, C. Q. Indicação geográfica e desenvolvimento territorial sustentável: a atuação dos atores sociais nas dinâmicas de desenvolvimento territorial a partir da ligação do produto ao território (Um estudo de caso em Urussanga, SC). Dissertação (Mestrado em Agroecossistemas) - Florianópolis: UFSC, 2008.

VIEIRA, A. C. P.; WATANABE, M.; BRUCH, K. L. Perspectivas de desenvolvimento da vitivinicultura em face do reconhecimento da indicação de procedência Vales da Uva Goethe. Revista Gestão, Inovação e Tecnologia, v. 2, p. 327-343, 2012. https://doi.org/10.7198/S2237-07222201200040001

VITROLLES, D. When geographical indication conflicts with food heritage protection. Anthropology of Food, v. 8, 2011. https://doi.org/10.4000/aof.6809

WIPO - WORLD INTELLECTUAL PROPERTY ORGANIZATION. World Intellectual Property Indicators 2018. Disponível em: <www.wipo.int/edocs/pubdocs/en/wipo_pub_941_2018.pdf>. Acesso em: 11 de abril de 2020.

Recebido em: 14/07/2020

Aceito para publicação em: 29/10/2020 